\title{
Rosas y espinas. Representaciones de las mujeres en el arte colombiano 1868-1910**
}

\author{
Roses and thorns. Representations of the women \\ in the colombian art 1868-1910 \\ Rosas e espinhos. Representações das mulheres \\ na arte colombiana 1868-1910
}

\footnotetext{
* Magister en Historia de la Pontificia Universidad Javeriana de Bogotá. Investigadora en temas de Historia cultural, Historia de las mujeres, Teoría de la representación, Estudios de Género e Historia del arte colombiano. Becaria del Ministerio de Cultura de España en la Estancia "Gestión y coordinación de actividades de difusión para los Museos Estatales" en Madrid, 2008. En la actualidad, es docente hora cátedra de la Universidad Javeriana Cali en el Departamento de arquitectura, arte y diseño, y de la Universidad del Valle en el Departamento de historia; así como curadora independiente en el arte de las mujeres artistas colombianas y extranjeras. Correo electrónico: luzadrianahoyosg@gmail.com

${ }^{* *}$ Este artículo se desarrolla en el marco de la investigación de 2011 titulada Mujeres Visibles/Mujeres invisibles. Representaciones de las mujeres en el arte colombiano 1868-1910, con el cual obtuvo el título de Magíster en Historia en la Pontificia Universidad Javeriana, Bogotá. Artículo de investigación recibido el 27/02/2015 y aceptado el 26/10/2015.
} 


\section{Cómo citar}

Hoyos, L. A. (2015). Rosas y espinas. Representaciones de las mujeres en el arte colombiano 1868-1910. Revista CS, no.17, pp. 83-108. Cali, Colombia: Facultad de Derecho y Ciencias Sociales, Universidad Icesi.

DOI: http://dx.doi.org/10.18046/recs.i17.1970 


\section{Resumen}

Abstract

Resumo

Este artículo expone los planteamientos principales y las conclusiones de la investigación "Mujeres Visibles/Mujeres invisibles. Representaciones de las mujeres en el arte colombiano 1868-1910”. El análisis de pinturas, dibujos y series litográficas de cuadros de costumbres durante el período escogido muestra cómo las representaciones de las mujeres legitimaron modelos diferenciados para los distintos sectores sociales. La metodología utilizada es propia de la Historia Cultural que estudia las representaciones y la difusión y circulación de las producciones culturales. Como categorías de análisis se usaron los conceptos de Pierre Bordieu: Campo, Distinción y Habitus que se aplicaron específicamente a la época estudiada y permitieron determinar la influencia que tuvieron las élites tanto en la producción de las obras de arte, como en la creación de prácticas que, asociadas a los manuales y a la prensa dedicada a la mujeres definieron formas de comportamiento que atribuyeron a éstas características morales y cristianas específicas. El estudio concluye cómo una gran parte de los retratos femeninos seleccionados definieron un modelo idealizado de mujer que se sumó a las estrategias de difusión establecidas por los grupos de élite.

PALABRAS CLAVE:

Representación | habitus | distinción | historia cultural.

This article presents the principal expositions and conclusions of the investigation "Women invisible Visibles/Mujeres. Representations of the women in the Colombian art 1868-1910". The analysis of paintings, drawings and lithographic series of pictures of customs during the select period shows how the representations of the women were legitimized by models differentiated for the different social sectors. The used methodology is own of the Cultural History that studies the representations and the diffusion and traffic of the cultural productions. The used methodology is own of the Cultural History that studies the representations and the diffusion and traffic of the cultural productions. Since categories of analysis used Pierre Bordieu's concepts: Field, Distinction and Habitus that were applied specifically to the studied epoch and allowed to determine the influence that the elites had so much in the production of the works of art, since in the creation of practices that, associated with the manuals and with the press dedicated to the women they defined forms of behavior that 
attributed characteristic moral and Christian specific these. The study concludes how a great part of the feminine selected portraits was defined by them a model idealized of woman who added to the strategies of diffusion established by the groups of elite.

\section{KEYWORDS:}

Representation | habitus | distinction | Cultural History

Este artigo apresenta as principais abordagens e conclusões da pesquisa "Mulheres Visíveis/ Mulheres invisíveis. Representações das mulheres na arte colombiana 1868-1910". A análise de pinturas, desenhos e séries litográficas de quadros de costumes durante o período escolhido mostra como as representações das mulheres legitimaram modelos diferenciados para os diferentes setores sociais. A metodologia utilizada é própria da História Cultural que estuda as representações e a difusão e circulação das produções culturais. Como categorias de análises usaram-se os conceitos de Pierre Bordieu: Campo, Distinção e Habitus que foram aplicados especificamente à época estudada e permitiram determinar a influência que as elites exerceram tanto e na produção das obras de arte, como na criação de práticas que, associadas aos manuais e à imprensa dedicada às mulheres definiram formas de comportamento que atribuíram a estas características morais e cristãs específicas. O estudo conclui como uma grande parte dos retratos femininos selecionados definiu um modelo idealizado de mulher que se u às estratégias de difusão estabelecidas pelos grupos de elite.

\section{PALAVRAS CHAVES:}

Rosas e espinhos | Representações das mulheres na arte colombiana 1868-1910 


\section{Introducción}

Mirar el pasado a través del arte permite un acercamiento a las representaciones que produjeron los artistas de una época determinada. Para el caso de las mujeres, durante el siglo XIX se les posicionó en un lugar idealizado a partir de diversos referentes morales y cristianos. Este artículo que parte de la investigación titulada Mujeres visibles/ Mujeres invisibles. Representaciones de las mujeres en el Arte colombiano (1868-1910), es uns versión sintética del estudio que se encargó de analizar obras de arte con el objetivo de mostrar cómo se representaba a las mujeres de los diferentes sectores sociales. En este sentido la pregunta a la que se enfrentó la investigación fue la siguiente: ¿De qué manera el arte desplegó formas de representación de lo femenino y cómo dichas representaciones se articularon con otros modelos de representación de las mujeres propios de las élites finiseculares?

Para el efecto, el período escogido entre 1868 a 1910 coincide con el momento de autonomización del campo artístico en Colombia que ocurre durante los últimos 30 años del siglo XIX. En 2002, la socióloga Acuña aseguró en su estudio que se puede hablar de una génesis del campo durante los últimos 30 años del siglo XIX con la formación de las diferentes Academias de artes como las Academias Vásquez y Gutiérrez que comenzaron a incorporar conocimientos del arte académico y posteriormente, con la fundación de la Escuela de Bellas Artes, legitimó el valor de la enseñanza artística y así mismo impartió los conceptos que definieron los parámetros del arte, proceso que ayudó a un cambio de estatus del artista a un nivel profesional. Para Acuña (2002), este proceso muestra la génesis de la autonomización del campo artístico y coincide con un momento político coyuntural. El Estado inicia su proyecto centralista de la Regeneración lo que significa la unificación de sus símbolos: un himno, un escudo, una sola nación. Es así como esta investigación se enmarca desde la apertura del primer curso de dibujo y grabado fundado por Alberto Urdaneta en el año de 1868, pasando por la fundación de la Escuela Gutiérrez en 1873, de la Escuela de Bellas Artes en 1886 y culmina con la Exposición Nacional de Bellas Artes realizada durante el primer centenario de la independencia en 1910.

Durante la segunda mitad del siglo XIX en Colombia, diferentes maestros fundaron academias de arte que no contaron con recursos oficiales pero que aportaron al desarrollo del oficio del arte y a su consolidación como profesión. Sería sólo hasta el año de 1886, cuando se creó definitivamente la Escuela Nacional de Bellas Artes bajo la dirección de Alberto Urdaneta, cuando se legitimarían el dibujo y la pintura como artes superiores, así como también la profesión misma del artista en Colombia. Por aquel entonces, en medio de la agitación social y política de una nación en proceso de modernización, los grupos pertenecientes a la élite ${ }^{1}$ buscaban diversos elementos de 
distinción frente a otras clases. Entre estos elementos de distinción se le dio especial importancia al estudio de las artes y a la práctica de las buenas maneras; en cierta medida, la educación de las mujeres hacía parte de estas prácticas, y las situó en el rol central del hogar y de la unión familiar.

Grosso modo, la educación durante el siglo XIX estuvo ligada al Estado, las élites y la Iglesia. Lo cual permite entender cómo en este contexto la educación fue un privilegio que favoreció a los sectores altos y mantuvo al resto de la población en un alto grado de analfabetismo. Este privilegio lo recibieron por supuesto las mujeres de élite que pudieron tener acceso a la educación. Solo a manera de contexto, se destacan algunos proyectos educativos que permiten esclarecer la influencia que tuvo la relación Iglesia-Estado en la instauración de estas reformas. Primero, durante el Olimpo Radical (1863-1880), -periodo en el que los liberales asumieron el poder-se presentó la reforma educativa de 1870 que fue la primera en definir la educación como una de las funciones del estado. Durante este periodo se contrató una misión pedagógica con profesores alemanes para iniciar las Escuelas Normales. Se establecieron 20 escuelas para varones y mujeres en las capitales de los estados federales. Estas escuelas encontraron una fuerte oposición pues se consideraron una amenaza para el catolicismo, además, la reforma por su carácter laico frente a la enseñanza popular no fue apoyada por la Iglesia ni por el mismo partido liberal que ya se encontraba dividido. Luego, con la reforma hubo un crecimiento en la tasa de alumnos entre 1873 y 1881 , se pasó de 26.610 a 71.070 . Las creencias religiosas no fueron del todo desechadas por los liberales; una buena parte de estos no eran anticlericales ni estaban de acuerdo con quitarle el control social a la Iglesia en medio de tantas guerras civiles que amenazaban la economía del país, y por lo tanto, la tranquilidad de la clase dominante en el poder. El catolicismo se concebía necesario para mantener la cohesión social. Tercero, el período de la Regeneración que inició el presidente Rafael Núñez en 1880 reforzó este ideal además de promulgar la concepción de un orden a partir de la centralización del poder como respuesta al federalismo. La constitución de 1886 permitió esta unidad, y a través del Concordato que se firmó con el Vaticano en el año 1887 se le devolvió el poder al clero. Además se le confió la educación a esta institución, se declaró. Por último, luego de La Guerra de los Mil Días ocurrida entre 1899 y 1902, que fue alentada por los liberales radicales se volvió a instaurar la centralización durante el gobierno de Rafael Reyes que se dio entre 1904-1909, durante este gobierno se logró en el campo de la educación la creación del Ministerio de Instrucción Pública (Helg, 1987).

en Colombia (1986) en el cual plantea cómo una clase conquistó socialmente a las demás a través de sus comportamientos. El autor explica cómo este comportamiento acompañó al proyecto centralista y triunfó como legítimo sobre la mentalidad de las provincias. En palabras del historiador: "se denota la victoria social del cachaco sobre las demás clases y modos de ser provincianos (...) Los cachacos consiguen el control de las reglas del buen hablar, (...) la suave imposición de gustos, modos, sensibilidades (...) Las buenas maneras, el buen hablar y el apego a la legalidad formal separa a los hombres del reino salvaje (Palacios, 1986: 44). 
En este sentido, queda en evidencia que Estado, Iglesia y élites debían asegurar el cumplimiento de un conjunto de normas y comportamientos que tuvieron difusión a través de la prensa dedicada a la familia y a la mujer y de manuales de comportamiento y urbanidad ${ }^{2}$, los cuales establecieron un modelo idealizado para las mujeres pertenecientes a las élites que podían acceder a este tipo de información, más no para el resto que pertenecían a otros sectores sociales.

El análisis de pinturas y dibujos entre 1868 a 1910, mostró en primer lugar, cómo se legitimaron las representaciones de lo femenino en la pintura. Y en segundo lugar, cómo a partir de las diferentes representaciones realizadas por los pintores en el período escogido, se desarrolló una jerarquización en la representación de la mujer con modelos diferenciados para los distintos sectores sociales.

El análisis se realizó a partir de imágenes tomadas como fuente para la investigación histórica con el fin de dar cuenta de la relación existente entre las manifestaciones artísticas y el contexto socio-cultural de la época estudiada. La investigación se realizó a partir de las metodologías propias de la historia cultural; esta corriente historiográfica se generó en los años 70 a partir de la Escuela francesa de los Annales y más precisamente responde a la NHC o Nueva Historia Cultural que comenzó a finales de la década de 1980 con el historiador estadounidense Lynn Hunt quien publicó un conjunto de ensayos que respondían a este nombre. Para Peter Burke: "La NHC es la forma dominante de la historia cultural (algunos dirían incluso que la forma dominante de la historia) practicada en la actualidad" (Burke, 2006:69).

El apelativo "cultural" es para diferenciarla de la historia intelectual pues no da cuenta de las ideas o los sistemas de pensamiento sino que se ocupa más precisamente del estudio de las representaciones, los imaginarios y las prácticas sociales como también de la difusión y circulación de las producciones culturales.

Se analizaron diversas obras que responden a modelos que la sociedad construyó para las mujeres de élite (niñas, jóvenes, adultas, ancianas) y así mismo para las mujeres de otras clases sociales y razas distintas a la blanca. El análisis de estas representaciones inserta la investigación en una de las líneas más actuales de los estudios de género que se ocupa de mostrar cómo las representaciones construyen un universo simbólico que enmarca el significado de lo que se consideraría como lo femenino, en una época determinada.

2. Hacia la mitad del siglo XIX aparecen las primeras publicaciones periódicas, la mayoría en Bogotá y Medellín. En un principio los periódicos fueron dirigidos por hombres y algunas mujeres colaboraron firmando con seudónimo o sus iniciales. Tal fue el caso de la escritora Soledad Acosta de Samper que tuvo que firmar como Aldebarán o Andina. Ella sería una de las mujeres más importantes en la difusión de estos diarios, pues dirigió siete periódicos durante el último cuarto del siglo XIX e inicios del XX. Sobre los manuales de comportamiento el más importante fue el manual de Urbanidad de Manuel Antonio Carreño que tuvo amplia difusión, incluso en buena parte del siglo XX. Sobre este tema se podrá revisar una mayor información en el primer capítulo del presente trabajo, pues se exponen las diferentes tendencias que tuvieron estos manuales y diarios a lo largo del período escogido. 
Fueron seleccionadas 200 obras entre pinturas al óleo y dibujos de diferentes artistas del campo artístico colombiano. También se escogieron series litográficas entre las que se destacan la serie editada en el año de 1878 sobre las acuarelas y dibujos del artista Ramón Torres Méndez que pertenecen a la mitad de siglo XIX y que fueron consideradas de vital importancia por dos motivos: el primero corresponde a que en estas imágenes se representan a las mujeres que no pertenecen al "Bello sexo" (campesinas, criadas, vendedoras en el mercado) y el segundo criterio de selección apunta a que la reedición de dibujos de mitad de siglo en una serie litográfica de 1878 indica que se mantiene la representación de características y tipologías de estas mujeres.

Las imágenes provienen de libros de arte, de la base de datos de la colección del Museo Nacional de Colombia que alberga una colección general de todo el país y de la base de datos de la colección del Museo del Tolima, que cuenta con obras poco conocidas de artistas como Epifanio Garay, Francisco Antonio Caro y Marco Tobón Mejía que corresponden al período de estudio.

Este estudio aporta nuevos elementos de análisis que tienen que ver con la construcción de lo femenino en las imágenes representadas a partir de la visión artística y estética de la época y de los condicionamientos a esta mirada impuestos por los gustos y hábitos de la sociedad colombiana. Además que aporta a los estudios referidos a la historia de las mujeres en el contexto colombiano, ya que hasta ahora no existe un análisis planteado desde la historia cultural que incluya la magnitud de representaciones que aquí se estudiaron, con el interés específico de mirar a las mujeres y sus modelos de representación.

El análisis se realizó agrupando las imágenes a partir de series temáticas, es decir: retratos, cuadros costumbristas, desnudos y alegorías (Ver cuadro 1). Cada uno de estos temas, en su mayoría se subdividen en grupos. Es decir, se analiza lo que representan la edad, raza, clase de las mujeres, y también cómo se evidencia la jerarquización entre éstas en relación con la mujer de élite y la criada, la mujer campesina y la mujer de la ciudad, la madre y la hija. A su vez se miran las relaciones que se presentan entre hombres y mujeres dentro del cuadro y los oficios o roles que realizan estas mujeres en las pinturas. (Ver cuadro 2). Es importante resaltar que entre las diferentes técnicas de las 200 obras escogidas se encontraron: óleos (125), dibujos (36), litografías (27), grabados (5), acuarelas (5), pasteles (2) y una sanguina (1). 
\begin{tabular}{l|l} 
CUADRO 1 & $\begin{array}{l}\text { Resultados porcentuales de los géneros pictóricos en los que aparecen } \\
\text { representadas las mujeres }\end{array}$
\end{tabular}



Retratos

Costumbrista

Alegorías

$\because$ Desnudos

Estudio

Paisaje

\section{\begin{tabular}{l|l} 
CUADRO 2 & Resultados porcentuales de roles y clases sociales de las mujeres
\end{tabular} representadas}



Modelo Ideal

Maternidad

$\because$ Heroínas

Escritoras

$\square$ Lectoras

Sensuales

Guitarristas

Criada

$\because$ Campesina

Afrodescendiente 
Como se puede apreciar, la mayor cantidad de obras son óleos, pues esta era considerada una técnica mayor, es decir, que implicaba según las normas académicas, más virtuosismo y esmero en la ejecución. El óleo y el dibujo constituían las técnicas pilares del academicismo. Cuando Felipe Santiago Gutiérrez en su Tratado del Dibujo y la pintura expone de qué se trata el capítulo dedicado a la técnica de la aguada, se refiere de esta manera:

En la cuarta parte hablamos sobre el sistema de pintura a la aguada, porque hay muchas personas, que no dedicándose profesionalmente a la pintura, propiamente dicha, querrán hacer uso del procedimiento del lavado o aguada, que es siempre más manual que el óleo y más fácil en su ejecución (Serrano, 1985:34; citado en Gutiérrez, 2006).

Cómo puede apreciarse, Gutiérrez definió la técnica del óleo como el nivel más profesional de la pintura misma, mientras que la aguada se reducía a una técnica menor que podía ser practicada por personas que no se dedicaran a la pintura como profesión. El orden de importancia que definen las explicaciones sobre cada técnica dan prelación al dibujo y el óleo.

Entre los pintores seleccionados se destaca que de los 34 artistas sólo dos eran mujeres y los demás hombres. Lo que demuestra que este campo artístico fue gobernado por hombres. Estos definieron como debía ser el ejercicio de las artes. Por esta razón, es necesario leer estas imágenes desde la perspectiva de género3 (Colorado, 2000: 12), ya que permite enriquecer el análisis y la reflexión sobre la manera como fueron vistas y representadas las mujeres en relación no solamente a su género sino en el entrecruce de relaciones de raza, cultura y clase, pues no se puede realizar una lectura sin conectar todas estas realidades. Así lo afirma la misma autora: "es posible que no sea la situación de género la que preocupe a muchas mujeres sino otras realidades como su situación de etnia o condición económica" (Colorado, 2000:19). Es aquí donde el género y las diferentes identidades se entrecruzan y permiten hacer una lectura más allá de la condición de ser "mujer" en una sociedad. Relacionando esta problemática con el universo pictórico al que nos adentramos, es donde cabe preguntarse ¿Cuáles son las mujeres que habitan este campo pictórico? ¿Cuáles son las mujeres visibles y cuales las invisibles?

3. La Psicóloga antioqueña Marta Colorado López explica en su artículo Géneroy perspectiva de género de qué se trata la introducción de esta perspectiva y lo que implica tenerla en cuenta para las diferentes investigaciones que involucren a las mujeres. Define que "la perspectiva de género se ha convertido en un nuevo modo de ver el ser humano, una nueva perspectiva desde la cual se reelaboran los conceptos de hombre y mujer; las relaciones entre ambos, sus funciones en la familia y en la sociedad" (Colorado, 2000: 12). 


\section{El retrato femenino y la construcción de un habitus}

Universalmente el retrato ha sido un género pictórico que se ha mantenido hasta nuestros días y que ha servido como instrumento de propaganda política y religiosa o como medio para recordar o idealizar un rostro según la importancia del rol de los individuos en las diferentes épocas y lugares. En un estudio del año 1969 de los historiadores y críticos de arte franceses Galienne y Pierre Francastel, coinciden en que se ha pasado de una noción del retrato como imagen fiel de su modelo "a la de un conjunto de signos donde cada uno, sea el pintor o el espectador, reconstruye a su gusto la imagen de una persona apenas determinada" (Francastel \& Francastel, 1988: 9).

En este sentido se puede asociar su definición con el doble poder de la representación, donde Chartier (1996), afirma que la representación significa en sí misma como también a través de la relación que existe con el que la mira. Es decir, en los retratos seleccionados se interpretan símbolos a través de las figuras femeninas representadas, y es así como mientras estas figuras se muestran "fieles a la naturaleza", según lo plantean los preceptos académicos, se puede notar que esa realidad que se muestra es una idealización.

Las características de las diferentes clases de mujeres de la época se exponen tras la mirada de un grupo de artistas que responde a las normas pictóricas de su tiempo y a las exigencias de la burguesía. Ahora bien, hay que tener en cuenta que durante todo el siglo se definió la imagen idealizada de la mujer de élite a través de la prensa y los manuales, escritos tanto por hombres como por mujeres. Las características de lo femenino que se privilegiaron tenían que ver con la mujer virginal y angelical, obediente, sumisa, sacrificada y virtuosa en las labores domésticas, con la exigencia hacia el último cuarto de siglo de una formación más culta para ser una mejor compañera pero sin dejar de atender sus deberes de madre y esposa.

Frente a estas mujeres eminentemente blancas o mestizas se presentan las "Evas", ligadas a otros roles como los de criada, campesina, prostituta o delincuente; modelos que no representan los ideales de la sociedad pero que su presencia en las imágenes distingue, diferencia y legitima el papel privilegiado que se le atribuía a las mujeres de élite. Por esta razón, se analiza cómo en las representaciones subsiste ese modelo privilegiado pero también, cómo tal modelo se refuerza al mostrar las diferenciaciones que persisten entre las mujeres en clase, raza y edad. El arte se constituyó en unos de los elementos de distinción de la élite, así, el retrato femenino quiso representar el ideal de la mujer decimonónico y ésta representación ayudó a la construcción de un Habitus, categoría planteada por el teórico Pierre Bordieu.

El artista colombiano y fundador de la Escuela de Bellas Artes, Alberto Urdaneta aseguraba que el arte tenía una misión específica y unas características estéticas y morales que definían el gusto de una sociedad. Para él las artes embellecían la vida del 
hombre, y tenían la función de civilizar al país. De esta manera se puede establecer que la pintura colombiana de finales del siglo XIX da cuenta del conjunto de gustos que distinguían a la sociedad burguesa. El retrato representó personajes ilustres del país, cultos e ilustrados. Esta burguesía eminentemente urbana legitimaba la cultura, el ejercicio y el estudio de las artes, y la práctica de las buenas maneras; con estas características, las clases altas ejercían una distinción frente a los habitantes del campo.

De esta manera, la burguesía en Colombia puede ser estudiada a través del concepto de distinción planteado por Bordieu a partir de la dominación que esta ejerce por medio del capital cultural. El sentido estético privilegia una clase y de esta manera impone un rasgo de distinción. La estética se va a constituir en una expresión distintiva de una posición privilegiada en el espacio social, cuyo valor distintivo se determina objetivamente en la relación con expresiones engendradas a partir de condiciones diferentes (Bordieu, 2002: 53).

Así, este autor propone que el gusto es la característica esencial por la cual se va a manifestar la diferencia, y se hace clasificable una persona de otra, un grupo de otro. Se puede establecer que para la burguesía colombiana de finales de siglo, el gusto va a ser una característica primordial para la distinción. A continuación, para complementar este análisis se definen las dos categorías relacionadas con la construcción del gusto propuestas por Bordieu: Habitus y Campo.

Establecer las características del campo de producción del arte permite entender las principales características del gusto de esta sociedad:

El campo de producción que evidentemente no podría funcionar sino pudiera contar con unos gustos ya existentes, propensiones más o menos intensas para consumir unos bienes más o menos estrictamente definidos, es lo que permite al gusto realizarse, ofreciéndole, en cada momento, el universo de bienes culturales como sistema de posibles estilísticos entre los cuales puede seleccionar el sistema de los rasgos estilísticos constitutivos de un estilo de vida (Bordieu, 2002: 228).

Evidentemente este campo de producción tendrá que estar en "la más perfecta homología" con el campo de consumo que establece la burguesía, ésta legitima el arte como elemento de distinción. En este sentido el arte y en particular el retrato se constituye en un bien cultural que ejerce un efecto de imposición simbólica a través de un trabajo de objetivación que lo consolida y legitima, claro está a partir de una clase que ejerce un poder de dominación en la constitución de este gusto como legítimo. Tanto el campo de producción como el campo de consumo van a privilegiar la formalidad, lo figurativo, lo académico y lo clásico en el gusto por el retrato y la pintura; lineamientos que complacen a la élite colombiana y a los cuales están sujetos también los artistas. La pintura fue adquiriendo un mayor valor con el transcurso del siglo y de los gustos 
de esta sociedad. Los lienzos hicieron parte de la decoración de las casas burguesas, y con ellos demostraron su ostentación y posición social.

El conjunto de las representaciones de las mujeres a través de la selección de pinturas escogidas para esta investigación, mostró cómo la sociedad decimonónica integró a las mujeres del Bello Sexo como instrumento de cohesión de la unidad familiar. En este sentido, estos retratos se convirtieron en un bien de capital cultural y tuvieron una función similar a la de los manuales y de la prensa en la formación del modelo "legítimo" de lo femenino. Estas pinturas, así como los manuales y la prensa se constituyen en un habitus ${ }^{4}$. Logran la interiorización de un modelo en la mentalidad femenina que se tradujo en la ejecución de diferentes prácticas que lo sustentaban. Las mujeres de los sectores sociales altos y medios se dedicaron entonces a la vida doméstica, a la maternidad y a la educación de sus hijos.

Es importante resaltar el concepto teórico de Habitus pues permite aclarar la manera como se realizó el análisis del modelo idealizado de las mujeres en la sociedad decimonónica. De esta manera se puede entender como el retrato femenino que representaba a las mujeres del Bello sexo aportó a la construcción de un habitus "que funciona como matriz estructurante de las percepciones, las apreciaciones y las acciones de cara a una coyuntura o acontecimiento que él contribuye a producir" (Bordieu, 2002:54).

Es decir, los retratos se convirtieron en una matriz que transfirió tradiciones, valores y comportamientos que se querían instituir de manera durable, esto es la reproducción de un modelo idealizado de mujer ligada al ámbito doméstico, con virtudes espirituales y morales, que le ayudaran a cumplir a cabalidad su rol de madre, esposa e hija. Las mujeres que posaron para los artistas pertenecían a las clases acomodadas. De esta forma los retratos funcionaban como elementos de distinción que además de plasmar las cualidades femeninas mencionadas, también mostraron los gustos de estas clases, pues en las obras se mostraban los mejores vestidos y adornos acordes con las modas que venían de Europa. Además se puede apreciar también como al interior de las casas se vivía entre lujosos cortinajes, muebles y objetos. Es así como las representaciones de las mujeres del Bello sexo muestran que las clases altas utilizaron el arte como un elemento de distinción que los diferenció de los otros sectores sociales.

En los apartados siguientes se muestra un resumen de las diferentes clasificaciones que arrojó el análisis de las representaciones que muestran como modelo predominante a las mujeres pertenecientes al Bello sexo y también las diferentes representaciones que se hicieron de las mujeres de otra clase y raza. 


\section{Rosas, lágrimas y sensualidad: niñas, jovencitas y jóvenes decimonónicas}

Se encontraron 14 pinturas de niñas y 27 entre jovencitas y mujeres jóvenes. Lo que representa un $7 \%$ en la totalidad de las imágenes con relación a las niñas y un $13.5 \%$ en relación a las jóvenes. Hay que aclarar que los retratos de jóvenes incluyen tanto a las mujercitas o a aquellas que están en el paso de la adolescencia a la mujer como también a las mujeres jóvenes que se muestran unas como esposas y otras a partir de modelos que aluden a la sensualidad.

Las diferentes representaciones tratan de mantener un modelo tradicional que responde a las características femeninas impuestas por la sociedad. Las niñas, jovencitas y jóvenes pertenecientes al Bello sexo se guardan al interior del hogar; en las niñas se admite el juego, la felicidad y la inocencia. En las jóvenes, la mayoría de imágenes muestran a mujeres pertenecientes al Bello sexo, que llevan del rol de hijas y esposas y se encuentran confinadas al hogar. Las representaciones muestran un mundo íntimo en el que se reflejan sentimientos como la tristeza y la melancolía; estas dan cuenta de un modo de sentir que se quería imponer como natural a partir de esta etapa de la vida, lo cual se reitera también en la prensa de la época. La heroína Policarpa Salavarrieta, está representada de manera que no transgreda la imagen virtuosa de las mujeres de la época, ya que no se muestra su carácter revolucionario sino su condición de mártir. Se encontraron también pinturas que van más allá de los límites impuestos a lo femenino con la representación de mujeres cargadas de sensualidad y erotismo. Estas jóvenes encarnan el temor del hombre a ser dominado. Los retratos no llevan ningún nombre como los de las mujeres de élite, pero se puede apreciar que estas son mujeres blancas que no pertenecen a estratos sociales bajos por sus ropajes y que simbolizan como la sensualidad es un rasgo eminentemente juvenil. Las escasas representaciones sobre el tema dan cuenta del tabú que existía al mostrar la desnudez de las mujeres como de la consideración generalizada del poder arrasador de la juventud, por esta razón tanto en la prensa, los manuales y la pintura se promueven el recato, las buenas maneras y se guarda a las jóvenes en el interior de sus casas.

Es preciso citar aquí al teórico Stuart Hall, pues plantea en su teoría de la representación ${ }^{5}$ que éste es un proceso que se constituye en una práctica que produce sentido y significa en la medida en que hay un intercambio entre los miembros de una misma cultura. Para el teórico el proceso de la representación ${ }^{6}$ está en la relación entre las cosas,

5. Revisar los conceptos teóricos de Stuart Hall sobre la Representación (IEP Instituto de Estudios Peruanos., 2002: 13-74)

6. La representación implica el uso del lenguaje, de signos, de imágenes que según Hall están por o representan cosas. Se cuenta en primer lugar, con las representaciones mentales, estas constituyen los mapas mentales que permiten darle sentido tanto a lo que se percibe como a lo abstracto. En segundo lugar se encuentra el lenguaje que permite compartir los mapas mentales a través de signos que constituyen los sistemas de sentido de cada cultura y en él se incluyen lo escrito, lo hablado y las imágenes visuales (IEP Instituto de Estudios Peruanos., 20O2). 
los conceptos y los signos; de esta forma, las representaciones que se acaban de analizar hacen parte de un convenio cultural, que a través del arte, la prensa y los manuales de buenas maneras, hizo posible el aprendizaje y la internacionalización de códigos, traducidos en actitudes y comportamientos que produjeron el sentido de lo femenino, y logró que un sector social se apropiara de estas representaciones para mostrarse y diferenciarse de los demás. Aspecto que se podrá apreciar también en el siguiente apartado que muestra cómo el modelo que se refuerza desde la niñez y la juventud, prevalece, con sutiles cambios en la edad madura de las mujeres a lo largo del siglo.

\section{Reinas y señoras. Escritoras, heroínas y otros oficios ¿inútiles?}

Las pinturas de mujeres adultas y de mediana edad representan el 32\% (64 obras) de la totalidad de las obras seleccionadas. En 52 de estas obras, se encuentra a la mujer como esposa, madre, y escritora. Los 12 restantes muestran otras mujeres de élite que no están asociadas con el modelo ideal pero que por su vestido distinguen su posición. También se representan mujeres que se alejan de este modelo: se encontraron representaciones de una mujer afrodescendiente, una campesina, dos lavanderas y un retrato que muestra a dos mujeres delincuentes. Lo que se puede notar al revisar estas imágenes es el lugar social de las mujeres de élite y como los modelos de esposa y madre las dignifican. A su vez, las mujeres que no pertenecen a esta clase se representan en la medida en que se hace referencia a la posición social dominante. Las mujeres afrodescendientes solo están representadas en un único retrato y las campesinas, obreras o mujeres del pueblo aparecen realizando algún oficio.

Se resume que el modelo de esposa y madre en las mujeres de élite es reiterativo y posiciona a la mujer en un lugar social que la subordina al ámbito doméstico. Lo cual ubica a la mujer en términos de género en un lugar apartado al del hombre. Lo femenino y lo masculino se conciben de manera diferenciada como si se tratara de un orden natural. La perspectiva de género (Colorado, 2000: 19) lucha por la igualdad entre mujeres y hombres en los diferentes campos de una sociedad. Esto indica como a partir de estas representaciones es imposible leer una equivalencia entre los géneros en este contexto pues se establecen roles y lugares específicos para las mujeres y para los hombres.

\section{Modos de representación de las mujeres campesinas y de clases populares}

Se analizaron 55 obras que representan a la mujer campesina y de zonas rurales. Estas resaltan tanto a los habitantes del campo como de la ciudad y para el caso de las mujeres es importante ver como se establece esa imagen de la mujer trabajadora y campesina 
en comparación con la mujer de élite. A partir del análisis anterior de los retratos en los que la mujer de élite es la protagonista, se hace necesario revisar otras temáticas del arte colombiano para encontrar a esas mujeres que se tornan invisibles o con poca notoriedad.

Para 1849, con la aparición del periódico El Museo que tuvo cinco ediciones, se empezaron a difundir las imágenes de costumbres y las colecciones litográficas. El autor más conocido de esta serie de imágenes fue el pintor y retratista autodidacta Ramón Torres Méndez7. Estas litografías se usaron en los muros de casonas, tiendas y posadas, a su vez, permitían que la gente santafereña perteneciente a las diferentes clases sociales se identificara con los personajes y las escenas representadas en estas imágenes. Para el investigador Efraín Sánchez Cabra los cuadros de costumbres de Torres Méndez, fueron también "expresiones de una tendencia generalizada en América con la connotación de género menor. Pero aun así constituyen el más vivo legado visual de la Nueva Granada en el siglo XIX" (Sánchez, 1987:127). El costumbrismo pictórico tuvo sus orígenes con las ilustraciones de las crónicas de viajes, que a cargo de artistas profesionales o aficionados en su mayoría europeos, comenzaron a representar durante comienzos de siglo escenas cotidianas, de lugares, de tipos de vestido de la gente del pueblo y de las ciudades. A lo largo del siglo este gusto se fue fomentando y difundiendo por toda América. Sobre estas láminas existen colecciones valiosas que realizaron pintores viajeros que muestran las costumbres y vida cotidiana de Latinoamérica, que fueron difundidas por toda América y Europa a través de la litografía ${ }^{8}$. Entre mucho otros, Sería Ramón Torres Méndez quien lograría darle la mayor expresión a este tipo de imágenes, durante toda la segunda mitad del siglo. Para la Primera exposición anual de 1886, el representante más significativo del costumbrismo fue este artista del cual se presentaron 24 cuadros inéditos y 36 litografías de la edición impresa en París por A. Delarue.

En cuanto a las temáticas "la imitación del buen salvaje, el gusto por lo pintoresco, espontáneo, anecdótico y el afecto por la rusticidad del campesino y las costumbres sencillas de la gente del pueblo, constituyeron los ingredientes universales del costumbrismo"(Sánchez, 1987:130). Una característica importante que también menciona Sánchez (1987) tiene que ver con la mirada moralista de los artistas frente a las nuevas

7. Pintor costumbrista, retratista, dibujante, miniaturista, caricaturista y grabador (Bogotá, 1809-1885). Hijo de artesanos, Torres Méndez realizó un inventario de las costumbres colombianas del siglo XIX, en lápiz, acuarela y grabado (Segura, 1979).

8. Efraín Sánchez Cabra hace una completa mención de estos álbumes litografiados a lo largo de América Latina en su libro Ramón Torres Méndez. Pintor de la Nueva Granada (1987) entre los cuales destaco algunos: En Argentina Picturesque Ilustration of Buenos Ayres y Montevideo (1820) del inglés Emeric Essex Vidal, Trajes y costumbres de la provincia de Buenos Aires $(1828,1838)$, del litógrafo ginebrino César Hipólito Bacle. En Cuba, las series Isla de Cuba pintoresca (1838-40) del francés Federico Mialhe y Los cubanos pintados por sí mismo (1852). En Ecuador Antonio Salas realizó varias escenas de costumbres en 1850 en compañía del francés Ernesto Charton publicadas en L'Illustration de París. En México, Costumres civiles, militaires et religieux du Mexique de Claudio Levati, publicada en Bruselas (1828). 
costumbres, ya que la tradición permitía el juicio sobre lo nuevo en referencia a modas, o hábitos de la sociedad que era mirado por los costumbristas con cierta sátira y mordacidad. Pero en general el costumbrismo nos ofrece una representación de los tipos sociales y de los lugares que habitaban.

El costumbrismo y neocostumbrismo fueron dos corrientes que se desarrollaron en su orden desde la primera mitad del siglo XIX hasta los inicios del siglo XX. Según afirma Pérez (2006) el costumbrismo se inició con la comisión corográfica en 1851 y con la tertulia El Mosaico que promovió una literatura de lo nacional hacia 1858 y tuvo como fin: "ilustrar las costumbres para dejar un testimonio de ellas en un afán por conocer y clasificar todo aquello que constituía la nación” (Pérez, 2006:298).

El género fue decayendo hacia finales de siglo por el auge de la pintura académica que privilegió el retrato como símbolo de distinción de las clases acomodadas. Sólo hasta inicios del siglo XX los pintores se interesaron nuevamente por estos temas pero con una diferencia, esta vez no buscaba clasificar los tipos de pobladores de las regiones de manera objetiva, sino que se realizaron pinturas académicas de gran formato y al óleo en las que se embellecían a los campesinos y exaltaban sus costumbres, a diferencia del carácter instructivo y de pequeños formatos y técnicas menores del costumbrismo de mitad de siglo XIX. Estas diferencias tan marcadas en cada corriente responden también a las coyunturas sociales y políticas que se dieron en cada siglo.

Según Pérez (2006), se puede notar como los campesinos son representados de una manera pasiva, con una vida apacible en el campo, lejos de los conflictos sociales. De acuerdo con el análisis de la autora, existe una idealización de las clases campesinas en la pintura, de manera que se mostraba un escenario rural controlado y sin conflictos, se trató de pintar una verdad aparente de la vida cotidiana: "el trabajo como actividad gratificante, un paisaje rural idealizado, unos campesinos limpios vestidos a la usanza tradicional, son algunos dispositivos que los artistas pusieron en juego para conformar un tipo de percepción en el que la pintura parecía ser una ventana a la realidad" (Pérez, 2006: 309).

En las obras seleccionadas se puede observar un mayor número de representaciones de mujeres de otras razas y escala social, lo interesante es analizar cómo se muestran estas mujeres y cuál es la imagen que se quiere representar de ellas, pues si bien es cierto que en este tipo de obras están mayormente representadas, hay que ubicar cual es el lugar social que se establece en su representación. Es decir ¿Qué labores desarrollan? ¿Aparecen hombres con ellas? ¿Cómo se representan estas mujeres en relación con las otras clases?

Entre las 55 obras que hacen referencia a aquellas mujeres que no pertenecían al bello sexo, se encuentran las siguientes técnicas: 19 óleos, 27 litografías, 5 dibujos, 3 grabados y 1 Acuarela. La técnica que se destaca es la litográfica (51\%), pues como se verá más adelante se hizo muy importante en Latinoamérica durante el siglo XIX, ya 
que permitía la difusión de las costumbres de los pueblos, incluso a otros países como Estados Unidos, Francia e Inglaterra, por medio de láminas e impresión de estas en periódicos. Los óleos se encuentran en menor porcentaje (32\%) y las demás técnicas dibujo, acuarela y grabados se presentan en menor porcentaje (16\%).

En el caso del pintor Ramón Torres Méndez todos sus cuadros contienen a tipos sociales y muestran sus rasgos, indumentaria y actitudes según su condición social, ellos son sus protagonistas, más que el paisaje. Estas imágenes pueden agruparse en varias series, destacándose las de tipos nacionales y otras en menor cantidad que se refieren a escenas de la vida cotidiana de Bogotá, de mercado, fiestas y escenas de viajes. Para el caso de estudio se escogieron diversas imágenes donde las mujeres fueran sus protagonistas. Se eligieron imágenes litográficas que corresponden a las ediciones francesa de A. Delarue, Victor Sperling, Leipszig de 1910 y una edición de 1878 donada por el Banco Popular al Museo Nacional de Colombia y que actualmente se encuentra dentro de su colección. Se escogen estas ediciones, porque a pesar de que las imágenes de estos cuadros de costumbres son en su mayoría realizadas por Ramón Torres Méndez a mitad de siglo, en el transcurso del periodo escogido (1878-1910) siguieron teniendo difusión en ediciones litográficas. La litografía siguió teniendo valor como representación de los tipos nacionales aun entrando a los albores del siglo XX. Se aclara que no sólo se usaron para el análisis imágenes de Torres Méndez sino que se incluyen también otros autores.

En el análisis se dio prioridad a las litografías pues representan la mayor cantidad de imágenes, a la par se hará mención de la representación de las mujeres en las otras técnicas como óleos, grabados, dibujos y acuarelas. El conjunto de imágenes muestran a la mujer campesina relacionada con el trabajo, sus oficios en el campo y la ciudad, como también establecen su relación con la élite y con el género masculino.

\section{Labores cotidianas, faenas solitarias}

Seis imágenes litográficas dan cuentan de la relación de la mujer con el trabajo cotidiano. Se puede notar cómo la mujer comparte esta labor con el hombre y también cómo en algunos casos realiza labores de manera individual. Las litografías muestran como generalidad a la mujer con un papel igualitario frente al hombre como fuerza de trabajo. La pareja de arrieros, pescadores o campesinos trabaja a la par para lograr su supervivencia. Los roles de género que se establecen en la clase alta y se dividen de manera particular en cuanto a los espacios de representación, no están presentes en el mismo sentido para las clases populares, ya que se muestran en el cuadro tanto hombres como mujeres en una relación igualitaria.

Estas representaciones reafirman como la historia de todas las mujeres no es la misma. Para las mujeres de clases sociales distintas a las altas y de razas diferentes a la 
blanca, no existe una condición dentro del ámbito doméstico ni sus labores corresponden al cultivo del conocimiento, el aprendizaje de las buenas maneras, la economía doméstica, entre otras. Para estas mujeres, según las representaciones, la fuerza de trabajo se divide de igual manera con el hombre y en estas labores consiste su cotidianidad.

\section{Espacios rurales, espacios urbanos}

Las litografías también dejan ver cómo se establece un lugar social desde la representación para las mujeres campesinas o de clases populares. Es interesante ver como se liga a las mujeres a unas labores específicas y cómo cuando no están realizándolas se les representa de una manera negativa, en algunos casos. Se analizaron 13 litografías en las cuales estas mujeres aparecen haciendo labores rurales y urbanas, las cuales se exponen a continuación.

Lo que se pudo encontrar en las litografías de la mujer en el campo es que tienen un carácter moralizante que representa una mirada que imagina a las mujeres campesinas haciendo unas labores en lugares específicos. Es decir, con las representaciones se destina un lugar a las mujeres campesinas, que debe mantenerse dentro de los límites del campo y que presenta una relación jerárquica frente a las clases altas. Estas obras hacen referencia a una vida apacible y tradicional en la que las mujeres participan de una vida en comunidad con costumbres arraigadas que tienen que ver con sus creencias religiosas y su recreación.

Por otro lado, las litografías que muestran a estas mujeres en la ciudad, las relacionan directamente con el campo y sus labores como mujeres trabajadoras; es en la ciudad donde deben ganarse la vida, así que están relacionadas con escenas de mercado en su mayoría. Si las mujeres no se encuentran en estos lugares, se las relacionan negativamente con temas de desorden público, es decir, juzgados o riñas callejeras. En estas escenas siempre aparecen hombres que juzgan su comportamiento. Lo cual indica como las litografías tuvieron un importante componente moral que caracterizó a los tipos nacionales y les atribuyó no sólo comportamientos específicos sino también espacios físicos a los que debían pertenecer.

\section{Representación de las jerarquías sociales}

En las litografías se evidencia el tema de las jerarquías entre las clases. Teniendo en cuenta el punto de vista que nos interesa, se nota como hay una clara distinción entre la mujer perteneciente al Bello sexo y la que no lo es. Esta distinción está marcada en la representación por el vestido y los roles asumidos por las mujeres en el cuadro. Según las obras analizadas se puede concluir como la élite se representa a sí misma como 
superior. Su posición se establece en referencia a la inferioridad de las otras clases, diferenciándose por su manera de vestir, su postura, la procedencia racial y su ubicación en el cuadro, ya que por lo general se les ve en primeros planos, o en referencia a los otros estratos, se representan con mayor altura.

\section{Mujeres al aire libre}

Una última tendencia en la representación costumbrista tiene que ver con los temas influenciados por Europa. En Andrés de Santa María se puede apreciar claramente esta tendencia, ya que vivió casi toda su vida en Europa, por lo tanto sus temas reflejan costumbres europeas que se diferencian de lo que podían presenciar los pintores en Colombia. De esta manera, las representaciones de las mujeres que hace Santamaría, reflejan cómo estas ganaban un espacio diferente del ámbito doméstico; Serrano (1978), afirma que no se tiene en cuenta desde el punto de vista crítico, el acento europeo de las obras de Santamaría, por esta razón lo encuentran incompatible con la nacionalidad colombiana. Comentarios como este muestran el cambio en la representación que se puede apreciar en las obras de este pintor, que también influenció con sus temáticas a otros pintores de su generación.

En las pinturas de Santamaría existe una clara influencia europea que logra representaciones con un tratamiento distinto al que se ha podido apreciar como modelo predominante en la pintura colombiana. Los temas son más refrescantes tanto en la estética, pues son pinturas con mayor iluminación y colorido, como en el tema ya que las pinturas abordan nuevas miradas que vagamente se filtraron en el arte colombiano, pues como se ha señalado, el arte tuvo un compromiso moralizante por un lado, y por otro sirvió como elemento de distinción de las clases acomodadas, lo cual marcó el desarrollo de temáticas en una vía que se adecuara a los modos de vida que se querían mantener. Con estas pinturas, se logra evidenciar cómo las mujeres ganaron un espacio que no era posible encontrar en las pinturas colombianas de la misma época por las misma razones ya explicadas, lo cual evidencia como el género femenino se ubicó de manera subordinada en unos roles específicos que se mantuvieron durante el siglo XIX e inicio del XX con leves cambios que no transgredieran los límite impuestos a lo femenino.

\section{Mujeres imaginadas, mujeres soñadas. Amantes sensuales y tentaciones desnudas}

Entre las 200 imágenes de obras analizadas en esta investigación, existen solamente $6(3 \%)$ de alegorías sobre mujeres, indicando un muy bajo porcentaje en este tipo de temática, que se podría imaginar en mayor cantidad por la idealización que se ha hecho 
del género femenino en la historia del arte universal. Idealización que se puede observar en las obras seleccionadas se ubica en el plano de lo real ya que estaba representada en roles sociales y no en una inspiración soñada por el artista de manera metafórica.

Otro tema importante son los desnudos encontrados que fueron 27 , los cuales representan un porcentaje del $13 \%$. Se concluye que para el período se realizaron pocos desnudos debido también a las prohibiciones de tener modelos en la Escuela de Bellas artes y así mismo en los espacios que existían antes de la fundación de la misma. Este tema era problemático para la sociedad de la época.

Aunque se realizaron pocos desnudos es importante analizar los que tienen a la mujer como modelo. Las obras terminadas que se encontraron fueron 9 que pertenecen a pintores como Francisco Antonio Cano y Andrés de Santamaría, aunque en su mayoría son estudios y bocetos sin fechar (18 dibujos).Se puede afirmar que el tema del desnudo fue muy problemático durante el periodo, pues como se ha podido ver a lo largo del texto, esto responde a que el arte estaba ligado a los discursos de las élites sobre la moralidad. Especialmente si se trataba de las mujeres que en las distintas etapas de su vida, se confinaban al hogar y al ámbito privado, debió ser escandalosa la desnudez femenina representada. En síntesis, el cuerpo de la mujer estaba estrechamente relacionado con su rol "natural" como madre, este debía cuidarse de manera que pudiera cumplir esta función social, al tiempo que las mujeres debían moderar sus pasiones y deseos.

\section{Consideraciones finales}

A lo largo de este texto se analizó como las representaciones de las mujeres que se constituyeron en Colombia entre 1868 y 1910, mostraron de manera diferenciada a las clases sociales, imponiendo figuras que permanecieron como modelos en la cultura simbólica del período.

Desde el Estado y la Iglesia se propuso un modelo de mujer dirigido a las élites, que se difundió a través de los manuales de conducta, la prensa y la educación y uno de sus rasgos fue atribuir a las mujeres diferentes características morales y cristianas. A partir del análisis de las representaciones, se pudo concluir que una gran parte de los retratos femeninos seleccionados presentan este como modelo predominante, lo cual demuestra cómo el arte se sumó a las estrategias de difusión que establecieron lo femenino durante el período. Aunque al mismo tiempo se reflejaron otros modelos que se desarrollaron a la par. Estos están evidenciados en las pinturas seleccionadas y destacan las figuras de mujeres sensuales, heroínas, escritoras y lectoras, entre otras.

Se encontraron 106 retratos femeninos de los cuales 94 representaron a las mujeres de élite. Por consiguiente, los diferentes retratos seleccionados de niñas, jóvenes, 
mujeres adultas y ancianas que pertenecían al Bello sexo, privilegiaron los roles de hijas, madres y esposas que reforzaron de manera idealizada las virtudes de la pureza, la inocencia, la sumisión y la resignación, en una galería de mujeres que se muestran estáticas, entre cortinajes y muebles lujosos, posando en algunos casos con sus mejores galas y adornos. Este tipo de retratos demuestra la importancia que se le dio a la mujer dentro del ámbito doméstico.

Como se pudo ver a lo largo del texto, el retrato se constituyó en un género que tuvo continuidad durante todo el siglo y su característica principal fue que representó a las élites y sus gustos marcando la diferencia de estas como grupo frente a otros sectores sociales. Por consiguiente, a través del retrato femenino se representó a la mujer idealizada según el modelo promovido desde las élites, lo cual ayudó a la construcción de un habitus.

Estas representaciones también dan cuenta de otros modelos que se resistían al tradicional. Entre los retratos de las jóvenes se pueden encontrar nuevas figuras ligadas a lo femenino que no son comunes en la época. Se encontraron unos pocos retratos de mujeres de marcado carácter sensual y erótico que muestran su cuerpo desnudo y miran al espectador de manera desafiante. Estas mujeres representan otra cara de lo femenino, pues están expuestas a la mirada y no se encuentran con los ropajes característicos dentro del ámbito doméstico. En estas representaciones se muestra un juego simbólico en el que la mujer está ligada a figuras bíblicas transgresoras de la imagen virginal como Eva y Salomé. En ellas se puede leer cómo la juventud y su belleza de cierta forma estaban satanizadas por la sociedad ya que ejercían un tipo de dominación natural sobre los impulsos masculinos, a la juventud se le temía por esta razón. De esta forma se reitera cómo el mantener a las mujeres jóvenes confinadas al ámbito doméstico y brindarles la instrucción moral y cristiana adecuada tenía sus fundamentos en esta mirada patriarcal hacia lo femenino.

Las heroínas, escritoras y lectoras se encuentran retratadas en poca cantidad, lo cual demuestra una ausencia en la representación de las mujeres cuando ejercen roles diferentes del tradicional. Sin embargo, llama la atención cómo en algunas de estas representaciones lo que se promueve son las mismas características femeninas del modelo idealizado como es el caso de las heroínas. Como ocurre con las imágenes de Policarpa Salabarrieta en las cuales se promueve el rol de mártir que se asemeja a las características virginales del modelo hegemónico, esta heroína no se representa por sus acciones revolucionarias sino por su acción de morir por la patria.

Teniendo claro cuál fue el modelo predominante de las representaciones en los retratos femeninos, llama la atención la escasa inclusión de imágenes de mujeres pertenecientes a otros sectores sociales en este género pictórico. Se puede establecer que estos sectores no fueron un tema usual en este género y los diferentes ejemplos que se encontraron resaltan las virtudes de las mujeres que no pertenecen a la élite a partir de 
un imaginario de las mismas, que las representa con facciones delicadas, en ambientes tranquilos mientras realizan sus oficios o caracterizándolas a partir de su indumentaria. Otra observación importante se refiere a la casi inexistencia de retratos de mujeres afrodescendientes, pues sólo existe un dibujo que muestra a Matea Bolívar, la aya del libertador. A partir de estos resultados se concluye como el retrato invisibilizó a unas mujeres y promovió en cambio una imagen hegemónica de la mujer blanca, virginal y de moral cristiana.

Contrastando estos retratos en los que se nota una ausencia de las mujeres de otros sectores sociales, se encuentran las obras costumbristas y neocostumbristas que sí introducen estas imágenes a partir de diferentes modos de representación. Para el caso de la serie Cuadros de costumbres realizada por Ramón Torres Méndez de 1850 que se reeditan varias veces durante el último tercio del siglo XIX y la primera década del XX persisten las imágenes de las mujeres del tipo costumbrista en las que se definen características de vestuario, oficios, vicios y costumbres; en el caso de las pinturas de grandes formatos al óleo, que pertenecen a la primera década del siglo XX se refiere a obras neocostumbristas que elogian y dignifican la labor de estas mujeres representándolas bien vestidas, limpias, en lugares tranquilos como los interiores de sus casas o haciendo parte del paisaje mientras realizan cualquiera de sus oficios en un entorno apacible y lejos de los conflictos sociales. Se puede concluir que a través de estas 55 obras se representó a las mujeres que no pertenecen a las élites de diversas maneras: en primer lugar, son mostradas ejerciendo sus labores cotidianas en una relación igualitaria frente a los hombres, por lo que se puede concluir que los roles de género que se establecen en la clase alta y se dividen de manera particular en cuanto a los espacios de representación, no están presentes de la misma manera para las clases populares, ya que se muestran en el cuadro tanto hombres como mujeres en una relación equivalente. En segundo lugar, las mujeres campesinas se muestran de una manera positiva mientras estén ligadas a los espacios del campo y el mercado, cuando estas no se encuentran en estos espacios se muestran de una manera negativa como cuando se representan en ciudad, donde son asociadas con vicios, riñas callejeras, juzgados o diferentes casos de desorden público. Se concluye como para las mujeres campesinas se querían destinar lugares específicos de representación para no romper los cánones establecidos. En tercer lugar, diversas pinturas establecen una jerarquización entre las damas de clases acomodadas y sus criadas o las mujeres campesinas en el mercado. En esta relación, las mujeres pertenecientes al Bello sexo se presentan de manera diferenciada desde su vestido y la posición en la que se ubican dentro del cuadro que las muestra con mayor altura en referencia a las otras mujeres que aparecen vestidas con atuendos sencillos y descalzas o con alpargatas, siempre al lado de su señora o mientras ofrecen a las damas de élite, diferentes productos en el mercado. Las pinturas representan, en cierto sentido, una 
categorización de las mujeres en las que prevalecen las características de las mujeres de élite como un rasgo de distinción y diferenciación frente a las otras clases sociales.

En cuanto a las temáticas de los desnudos y alegorías, las obras encontradas fueron relativamente pocas y representan solo el $16 \%$ de la totalidad de las imágenes. El tema del desnudo fue muy problemático en el ambiente artístico de la Escuela de Bellas Artes y solo hasta 1904 fue aceptado que hubiera modelos al natural. Por esta razón, los óleos que se encuentran de mujeres desnudas son cercanos a esta fecha y representan generalmente tres posturas: la mujer como amante, la mujer como tentación y la mujer vista de manera naturalista como parte del paisaje sin ningún componente erótico. Las alegorías son sólo el $3 \%$ de la totalidad, por lo que se concluye como las mujeres se imaginaron no dentro del plano de la fantasía sino dentro del plano de lo real, ya que se idealizó representada en roles sociales.

Como se ha podido apreciar, el arte mostró la diferenciación entre las clases y promovió la representación de las élites, pero éste no fue un fenómeno que se dio a la ligera, sino que tuvo como sustento la consolidación del campo artístico que tuvo su apoyo también desde los sectores más altos e influyentes de la sociedad. Durante el periodo escogido se consolidó este campo gracias a la formación de lugares institucionales que se lograron a partir de proyectos que nacieron de grupos elitistas con apoyos oficiales. Con la formación de las Academias y finalmente la aparición de la Escuela de Bellas Artes se dio paso a un nuevo estatus para los artistas, que se conformaron en un grupo más sólido a partir de la enseñanza del arte académico. De esta forma, la figura del artista respondía a un campo específico mediado por premisas instituidas por la élite. A la luz de los conocimientos académicos, el arte no sólo debía ser copia fiel de la naturaleza, sino también enaltecer los comportamientos morales. Es así como la consolidación del campo del arte en Colombia coincidió con las ideas conservadoras de la Regeneración, de manera que también unificó y centralizó los discursos estéticos en la Escuela de Bellas Artes. Por esta razón, se puede notar como el grupo de pintores que realizó las obras analizadas recibieron una enseñanza exclusiva académica desde la Escuela y en sus viajes a Europa, donde no miraron las vanguardias artísticas sino que asumieron directamente los conocimientos académicos de las escuelas Francesa y española a las que asistieron, aprendiendo directamente de sus maestros. En cuanto al panorama de las exhibiciones de arte en Colombia, donde se expusieron las diferentes obras de arte producidas en el periodo, fueron importantes las que se llevaron a cabo desde la fundación de la Escuela de Bellas Artes, pues fue desde este escenario en el que se conformó un grupo de artistas que respondía a los lineamientos académicos y en el cual se generaron los elementos necesarios para que la crítica de arte empezara a generar un discurso público de lo que debía ser el arte. Estas muestras le dan un valor a las obras de arte, pues se define un lugar específico de exhibición que además fue ganando la aceptación de un público que se fue formando en la medida en que se iban 
produciendo estos espacios; finalmente, se demuestra también cómo el conjunto de estas exposiciones va consolidando la configuración del campo artístico, con la Academia y un grupo de artistas y críticos que establecieron las características específicas del arte y un discurso alrededor de la obra.

\section{Referencias}

ACUÑA, R. (2002). El papel periódico Ilustrado y la génesis de la configuración de un campo artístico en Colombia. Tesis de la Maestría en Sociología, 89-96. Bogotá: Universidad Nacional de Colombia.

BORDIEU, P. (2002). La distinción. México: Taurus.

BURKE, P. (2006). Peter Burke, ¿Qué es la historia cultural?. Barcelona: Paidós.

CHARTIER, R. (1996). Escribir las prácticas. Barcelona: Paidós.

COLORADO, M. (200o). Géneroy perspectiva de género. Conflictoy género. España: IPC de la Corporación de Promoción Popular.

FRANCASTEL, G., \& FRANCASTEL, P. (1988). El retrato. Madrid: Cátedra.

GUTIÉRREZ, F. S. (2006). Tratado del dibujo y la pintura. México: Fondo Cultural para la cultura y las artes, CONACULTA.

HELG, A. (1987). La educación en Colombia: 1918-1957. Primera. Bogotá: Universidad Pedagógica Nacional.

IEP INSTITUTO DE ESTUDIOS PERUANOS. (2002). Taller interactivo: prácticasy representaciones de la Nación, Estado y Ciudadanía en el Perú. El trabajo de la representación. Perú: Cultural Representations and Signifying.

PALACIOS, M. (1986). Estado y clases sociales en Colombia. Bogotá: Procultura.

PÉREZ, A. C. (2006). Imágenes sobre la cotidianidad de los campesinos del altiplano central. Colombia, 1919-1940. En: La Nación en América Latina: De su invención a la globalización neoliberal. Michoacán: Instituto de investigaciones históricas.

SÁNCHEZ, E. (1987). Ramón Torres Méndez, pintor de la Nueva Granada 1809 - 1885. (: , 1987), 127. Bogotá: Fondo Cultural Cafetero.

SÁNCHEZ, E. (1987). Ramón Torres Méndez, pintor de la Nueva Granada 1809-1885. Bogotá: Fondo Cultural Cafetero.

SEGURA, M. (1979). Gran Enciclopedia de Colombia del Círculo de Lectores. Tomo de biografías. Obtenido de lablaa.org: http://www.lablaa.org/blaavirtual/biografias/torrramo.html

SERRANO, E. (1978). Andrés de Santa María. Mambo: Carlos Valencia Editores. 